\title{
Sonia Vandepitte*
}

\section{Translating instructive texts}

\begin{abstract}
Starting with Werlich (1982), many researchers within text linguistics and document design see instructive texts as a category that is different from persuasive texts. Others do not include either in their main typologies (e.g. Bonnet et al. 2001). This paper will claim, however, that instructions are a particular subtype of persuasive texts: instructing people is also persuading them to do something in a particular way or in a particular situation or in a particular order. Consequently, all features characteristic of persuasion (e.g. Aristotle $4^{\text {th }}$ c. BC, Bettinghaus 1968, Dacheux 1994, Whalen 1996) also appear in instructive texts. Drawing from a learner corpus of materials used in the Trans-Atlantic Tech Writing / Translation Project (Maylath et al., 2005, in press), in which Flemish students translate English instructive texts written by American students into Dutch, the paper will discuss the problems involved in the translation of two relevant persuasive characteristics of instructive texts: expertise and positive audience-orientation. For the former, attention will be paid to message form, structure and strategy, while the latter will lead to considerations of both individual interpretation differences and cultural differences.
\end{abstract}

\section{Instructive texts as a main text type?}

In the literature, two approaches to instructive texts can be distinguished: one in which instructive texts constitute a main text type and the other in which the instructive texts do not get that high a status. The former is exemplified in Werlich (1982), who sees instructive texts as one clearly distinct type of text among the five main categories: description, narration, exposition, argumentation and instruction. Descriptive texts have an informative goal and are usually 'tenseless'. The same informative goal can be found in narrative texts, but these are usually

\footnotetext{
* Sonia Vandepitte

University College of Ghent

Translation Studies

Groot-Brittanniëlaan 45

B-9000 Ghent

sonia.vandepitte@hogent.be

Hermes - Journal of Language and Communication Studies no 40-2008
} 
expressed in the past tense: there is a narrator who informs about a past event. Explanatory texts, too, are informative, but they contain many causal links and function as explanations. Another main text type with many causal links is the argumentative type. Its purpose, however, is not to inform but to convince people. Argumentative texts attempt at persuading people that the ideas expressed should also be upheld by the audience. The final text type recognized by Werlich is that of instructive texts. They are said to be directive: the writer's aim is for the reader to be able to do something.

Another view is that instructive texts do not constitute a main text type at all. In Bonnet et al. (2001), only three text types are distinguished: narrative, informative and argumentative texts. Görlach (2004), on the other hand, has a list of over 2,000 text types, each type having its own specific characteristics, compiled from a grid that is based on 25 encyclopaedic components.

This paper will claim, however, that texts do not belong to particular text types as such, but had rather be described in terms of sets of features. On this view, it will be claimed that some of the text features appearing in instructive texts typically belong to the set of persuasive text features. The claim will be supported by two arguments:

- Instructive texts contain typical persuasive features.

- The translation of instructive texts itself reveals that persuasion is an important criterion for the choice between different translation variants.

\section{Persuasive features in instructive texts}

Although instructive texts do not need to create much desire with the reader, they do need to persuade readers to do something in a certain way, to do something in a certain order, not to skip any steps and to do something with certain materials.

Persuasive features are typically those that are found in advertising. One of the best-known models describing persuasion is the AIDA formula, which textbooks on business communications typically suggest adopting. The acronym stands for draw Attention, keep the Interest going, create Desire and Action. 
In instructive texts, these features are present, too, and readers take a central position (American Council on Consumer Interests 1993): readers find many visuals that draw their attention, such as warnings preceded by various sorts of symbols. Readers are also drawn into a relationship of trust: they are addressed personally, they are congratulated on buying a special product, they find themselves in a positive atmosphere which keeps their interest going. At the same time instructive texts create new desires. One of the hidden persuaders (to borrow Packard's term, 1957), for instance, is the compilation of instructions for different versions of a product into one booklet. Customers see all the other options and the potential of better developed versions. Finally, instructions are clearly action-directed: they present explanations why one should do a particular thing and, in particular, they direct readers to perform actions in a certain order, with a certain material or in a certain way.

To the AIDA-model, other phases (such as conviction and satisfaction) were added, dropped and rearranged. The most significant improvement of the model was its reduction to three steps, however, now known as the CAB-model, standing for Cognition (Awareness or learning), Affect (Feeling, interest or desire) and Behaviour (Action). Along with this development came a more flexible view of the order in which the steps are taken. Now it is suggested that different arrangements of the model might prove more effective for different consumer to product relationships. Whichever order is adopted, however, it is clear that instructive texts, too, reveal the same steps.

But there are more persuasive features in instructive texts and it is Aristotle's rhetoric which leads us to them. He focuses on ethos (the speaker's credibility), pathos (the listener's emotions), and logos (the message). With Dacheux (1994) and Whalen (1996), it is possible to look into the features that characterize a person's credibility. While Whalen stresses that persuaders will need to create active pictures in the mind of their audiences, it is clear that all three writers stress the following two characteristics of a credible person: expertise and positive audience orientation. Both will be discussed and illustrated in instructive texts, below. 


\subsection{Expertise in instructive texts}

Instructions can be said to be expert if the message focuses on three elements. First, expert instructions draw attention to the main item. Although instructions may introduce related products, this type of elaboration may confuse readers' understanding if it becomes too long. Secondly, the expert instructional message focuses on the product as a whole. Instructions sometimes need to go into detail about parts of products or about one particular type of procedure. Since readers usually buy a product to use it and not to analyse one of its components, they expect that the instructions will explain all its features. Finally, if a product offers different possibilities, these, too, will be explained in expert messages. Excellent instructions give clear explanations of all activities envisaged and collect the technical words used in glossaries. The explanations are as explicit as they need to be, there is the audience-appropriate level of redundancy and there are illustrating examples. The writer's expertise is also apparent in the form of the instructions: there is ample use of visuals, such as figures, schemes, pictures, boxes, tables, different font types and sizes, page layout and ordering devices such as subtitles. Extremely important is accuracy and readers should not discover flaws, as in example 1 below:

(1) Om het risico van elektrische schokken te verminderen dient u h:et apparaat uit het stopcontact te halen, voordat het u schoonmaakt. (Ericsson, Mobile Phone, T29s, p. 87)

(To reduce the risk of electrical shocks, you need to take the plug out of the socket, before it cleans you),

In addition, the message is structured in such a way that a reader clearly sees an introduction and a set of instructions for the actions to be performed, accompanied by explanations. Sentences are simple and short, and imperatives are the clearest means to express the series of actions to be performed. Steps are ordered logically, usually chronologically, and numbered.

\subsection{Positive audience-orientation in instructive texts}

Apart from showing the producers' expertise, instructions also reveal a positive orientation towards their audience. Since persuasion only takes place in environments which are safe and positive (Whalen 1996), instructions have introductions which create the non-threatening environ- 
ment and make readers feel good about themselves. They address the readers personally and they present arguments why readers should follow instructions closely or just remind them of those reasons:

(2) Introduction

If you are looking for a quick and easy addition to your next meal, try a salad. These instructions will guide you in the process of creating a fresh and nutritious salad that is tailored to your personal likes and dislikes. Starting with a few basic ingredients you can create an endless number of quick and easy to prepare culinary delights. The first step is to choose the type of greens that you will use. The second step is to choose the vegetables, cheeses and meats that you may have available to you. Next a dressing can be made using a basic recipe, which will be spiced up with the addition of your choice of flavorings. Final preparation will include preparing your ingredients and tossing your salad.

Without a good transmission a motorcycle will not move. To get the most out of a transmission and to save the hardships of having to buy a new one, preventative maintenance is necessary. With proper care, the transmission should last well beyond the lifetime of any motorcycle. These instructions give, in clear detail the proper care of the transmission that the modern day motocross bikes have. In particular, these instructions refer to the 1997 - 2003 Yamaha YZ125.

If instructions start by congratulating the readers on the purchase, the readers' past actions (buying the product) will be positively confirmed. Sometimes introductions also mention their special targets:

(3) These instructions are designed for someone with limited baking knowledge.

Readers of such special audiences will feel that their individual needs are addressed. In later passages, for instance, in the face of many warnings, a non-threatening situation is created by introducing positive features and appropriate humour. Warnings themselves are phrased as carefully as possible. As it draws attention to a message of danger, the atmosphere (or tone) of the text may change radically. Rather than predict a situation of gloom and doom, rather than employing a series of 'don'ts', the reader is cautioned, and usually an explanation is given:

(4) CAUTION: Microwaving the cream cheese in the foil wrapper may damage the microwave. 


\section{Persuasion as a criterion for the translation of instructive texts}

The translation of instructions itself supports the view that instructive texts are persuasive texts: persuasion itself is an important criterion in the choice between different translation variants.

Consider the following translations from a corpus compiled during seven years of transatlantic collaboration between Technical Writing students at the University of Wisconsin-Stout and Hogeschool Gent Translation students (Maylath, et al. 2005). This corpus consists of over one hundred instructive texts created by the American students and their translations by the Ghent students. Examples 5-7 show formal features that do not lead to formal equivalence. Either words or even whole messages have been deleted or lexical items have been replaced by others:

(5) Take a knife and a board and chop the onions

$\varnothing$-versnipper de ui

(Ø - chop the onion)

(6) Warning: mixture and oven will be hot! Use oven mitts! $\varnothing$

(7) CAUTION!!! The blade of the utility knife can be very sharp! Make sure care is given when using it!

PAS OP! Een breekmes heeft een heel scherp lemmet. Let goed op wanneer je het gebuikt.

(CAUTION! A utility knife has a very sharp blade. Take care when you use it. )

In utterance 5, the reader is told to take a board and a knife in order to chop an onion. For many adult Europeans, however, to get an instruction saying one needs a board and a knife to chop an onion is similar to receiving a very patronizing remark: it is only children who do not know that chopping onions requires the use of a board and a knife, and, indeed, you will probably find this type of instruction in children's or learners' cookery books only. Utterances 6 and 7 are clear examples of warnings, which are often expressed explicitly in US instructions. The explicitness also seems to be doubly expressed by means of the numbers of exclamation marks (on its undesirability, see Mousten et al. in press). Again, to a Belgian audience, this looks childish, and the translator opts for just one exclamation mark. Therefore, although instruction manuals favour repetition over referring expressions (Cook 1992), it is 
clear that target texts do not typically show a similar level of explicitness and translators do not always imitate the repetition.

Let us now look at the following series of corpus measure expressions and their Dutch translations:

(8) inches, gallons, 120V, 350 degrees Fahrenheit

$\mathrm{cm}, \mathrm{l}, 220 \mathrm{~V}, 180^{\circ} \mathrm{C}$

(9) $16 \times 6$ inches

$40,64 \times 15,24 \mathrm{~cm}$

$40,6 \times 15,2 \mathrm{~cm}$

$40,5 \times 15 \mathrm{~cm}$

(10) $1 / 4$ measuring cup

1/4 maatbeker

$1 / 4$ kopje

3 eetlepels

(1/4 measuring cup

$1 / 4$ cup

3 spoons)

Translators select the translation option which makes it easier for their readers: inches are translated into centimetres, gallons into litres, Fahrenheit degrees into centigrade and the voltage of $220 \mathrm{~V}$ common in Europe is used rather than the one utilized in the USA (120V). Similarly, literal translations of measurements that yield numbers in centimetres with two decimals are not frequent: there are no common measuring instruments for them. It is, therefore, necessary to round off these figures.

Foods can be replaced by foods available in the target text culture, so that the readers do not need to order special American foods in order to prepare a particular recipe:

(11) Graham cracker crumbs

broodkruimels

(bread crumbs)

American telephone numbers for a Belgian audience, too, do not make much sense. Translators may therefore opt to delete them or, if possible, replace them by references to local shops / dealers / manufacturers so that the more local reference may persuade the reader into making contact: 
(12) American telephone numbers

$\varnothing$

(13) Ozark Trail Map Compass

Wandelkompas

(Hiking compass)

In example 13, Ozark Trail refers to a hiking route in Missouri and it is also the name of the manufacturer who produces many other camping/outdoor objects besides the compass. A translator thinking in terms of semantic equivalence only, will thus opt for Kaartkompas voor het Ozarkwandelpad (Map compass for the Ozark Trail). This may, indeed, be the best translation choice for a Dutch-speaking audience, especially if the text is to be read by Dutch speakers when they are in the neighbourhood of the Ozark Trail. Its advantage is the presence of the company name in the translation. But in all other cases, to readers who may never walk the Ozark Trail in their lives but still be interested in the purchase of that particular compass, the reference to the Ozark trail does not make much sense. The Ozark Trail is not known to most Europeans, and although Europe has its own long-distance hiking paths, it is not certain whether referring to just one of those would be in the company's best interests. Another question arises: to what extent does an Ozark Trail Map Compass differ from an ordinary hiking compass? Compasses are usually used to look for the corners of the earth. Consequently, if the differences are minimal, is a hypernym not the most acceptable translation into a culture that is different from that in the source text? A compass is, indeed, thought of as something that is normally used for more than one map. Therefore, instead of choosing the equivalent phrase, a translator may, conversely, opt to refer to the hiking activity only and produce the translation wandelkompas (hiking compass). Considering its status as the title of an instruction guide - meaning that people need to be enticed into reading the instructions - its brevity may be more attractive for the readers. Admittedly, one disadvantage remains: this translation does not feature any company name at all, and it is doubtful whether any compass producing business will be happy with a translation in which its image is less apparent.

The reason for all the changes in the examples above is mainly the translator's positive reader-orientation. Measurements expressed in units that are not the ones that a reader is familiar with are notoriously 
difficult. They are one type of culture-specific references. Foods, telephone numbers, geographical references, materials, and so on, are others. Geographical references are often generalized as in the Ozark Trail map compass example.

How can we explain these features? Using a translation model that combines both a cognitive view (Gutt 2000) and a functional or skopos model (e.g. Reiss/Vermeer 1984/1991, Nord 1991, Gorlée 1994, Koller 1997), three translation stages are recognized (Figure 1): 1 . the circumstances that lead to a translation event, 2. the event itself in which six cognitive environments are recognized (source text commissioner, writer and audience, and target text commissioner, writer and audience) that cause a source text to be translated into a target text, and, 3. the circumstances that result from the target text's presence in its community (Vandepitte, in press).

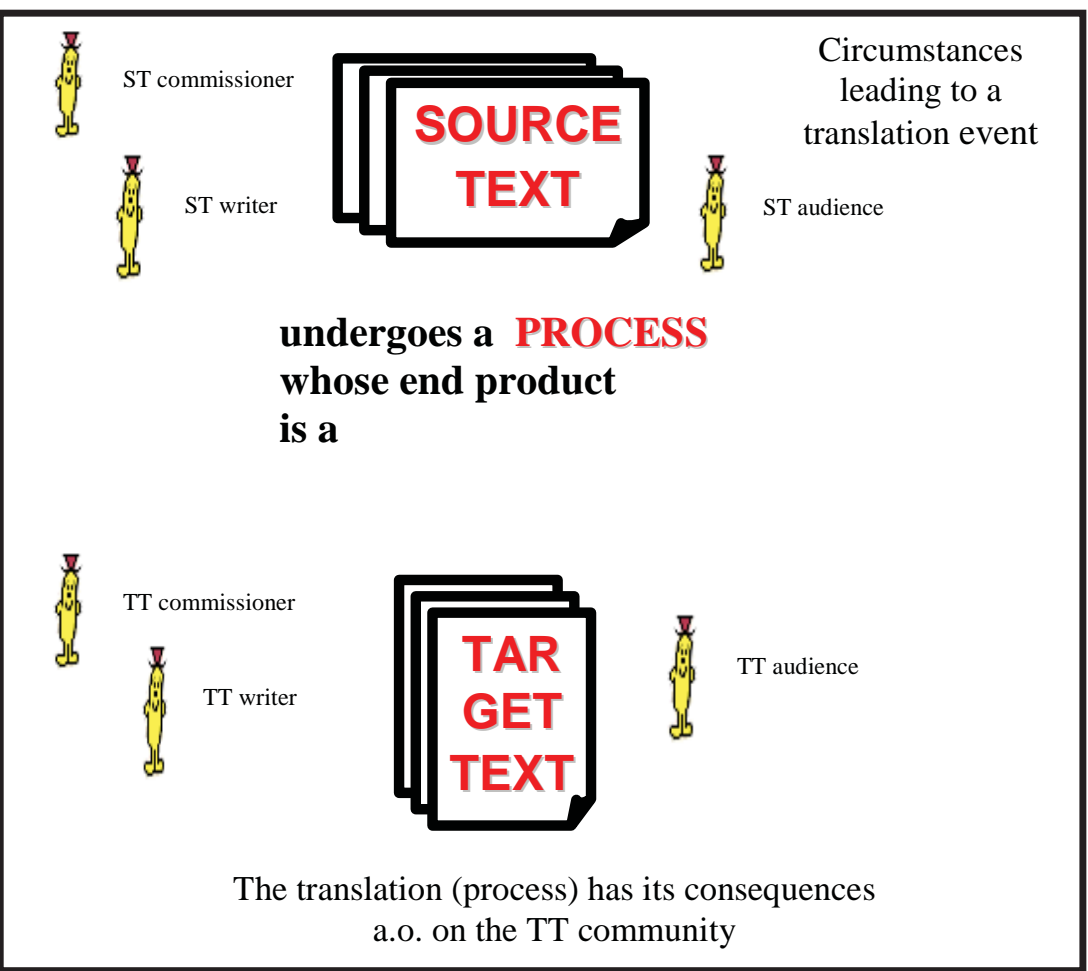

Figure 1. Translation model 
The translation situation for persuasive texts can be made more specific. The appellative character of a persuasive text (Jakobson 1960, Nord 1991) aims at its audience performing an action. Consequently, the source text audience is expected to perform an action, and so is the target text audience (Figure 2).

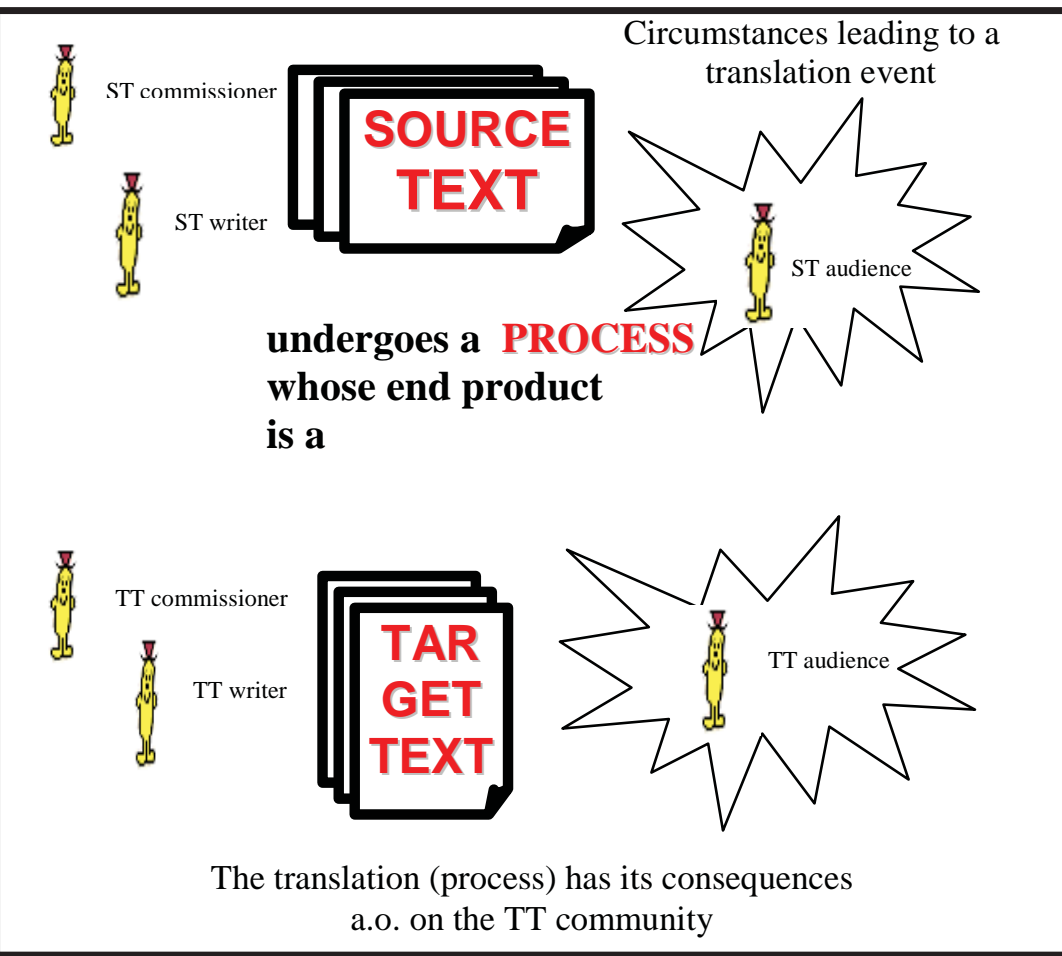

Figure 2. Translation model for persuasive texts

It is these expectations of different audiences that lead translators to decisions that do no longer show any formal equivalence or any semantic equivalence between the source and target texts, but only functional equivalence (Nord 1991, Gutt 2000). If Flemish translators see telephone numbers of American addresses, do they need to keep these numbers, invent some Flemish local numbers or use the numbers of similar Flemish companies? 
To conclude, translating instructive texts is translating positive audience-orientation and it is translating expertise. The translation strategy to be adopted in the translation of instructive texts is clearly not that of formal or content equivalence. Instead, the text needs to be adapted "to suit a particular reception situation” (Pym 2004:1), in other words, it needs to be localised.

\section{Text typologies}

If we took Görlach's text typology grid of over 2,000 text types (2004), which is mainly based on encyclopaedic components, the result would be that instructive texts on various semantic fields would fall into clear distinct categories and would not be regarded as a category on their own. Indeed, their referential content, i.e. the denotations to which the words of the message refer or the so-called propositional content of the sentence, will represent states of affairs that are quite different from one another, as exemplified in the two sentences below:

(14a) Carefully remove the staples from the sunroof kit box with a pair of pliers.

(14b) Students preparing a doctoral dissertation in the field of translation studies are invited to apply. To do so, please fill in the electronic application form (including the attachments) and send it to the address below by 1 May 2007.

In (14a) the reader receives information about a possible world in which somebody does something (removing staples from a box) and how this is done (carefully, with an instrument). Although, perhaps, the person referred to in (14b) performing the action of filling in the form may be the same person who is removing the staples from the box, a completely different possible world is pictured. It is one where there is also clear reference to a time, a place and a reason. Other instructions may stress certain characteristics such as quantitative data, the complexity of a state of affairs and its relation to other states of affairs, and so on.

Yet, all instructive texts also share a couple of important features. The features that they have in common, are not related to the semantic content, however, but rather to pragmatic meanings or especially to writerrelated meanings. Readers of both (14a) and (14b) will know, thanks to the context and the imperative in the message, that the writer considers 
a state of affairs as non-factual but as a possible world. In addition, both express the writer's expectations from the reader, i.e. the writer expects the reader to perform this action of removing the staples. To the writer of (14a), the state of affairs in which the reader removes the staples in a certain way is desirable, while the writer of (14b) expects the reader to fill in a form and send it somewhere before a certain date.

Consequently, it can be said that both instructions convey different referential features, but similar writer-related meanings: both instructions hold information about the writer's attitude to the proposition or state of affairs. At the same time, the state of affairs expressed involves the reader as an agent and the instructions therefore also express the writer's attitude to the reader. One utterance thus expresses diverse types of meanings simultaneously (for more meanings, see e.g. Vandepitte et al. 2006).

A text, consisting of a multitude of sentences, therefore, conveys a large compilation of pieces of information that interact with one another. If texts show similar information features, they can be said to belong to the same type of text. This simultaneity of different features within one text type supports Görlach's componential analysis, which does take into account the simultaneity of different text features. Whether it is the semantic information or rather one of the writer-related pieces of information that should function as the first criterion for a text typology, is, however, still a debatable question.

\section{Conclusion}

To conclude, instructive texts are clearly not purely informative. Like argumentative texts, they feature persuasive characteristics. For the translation industry, this is a factor not to be disregarded easily. Since persuasion is related to culture, and cultures do not translate easily, it is not clear whether resorting to controlling instructive texts in order to globalize them efficiently and cheaply will be effective in the long term: their persuasiveness (like any other persuasive test type) will decrease, as they get longer and as they are controlled to a higher degree.

Finally, this study has also shown how translation studies may contribute to text studies: it is the translation choices themselves that have pointed out the persuasive characteristics of instructive texts. 


\section{References}

American Council on Consumer Interests 1993: Product manuals: A consumer perspective. In Advancing the Consumer Interest (ACI), 5/2.

Aristotle $4^{\text {th }}$ c. BC: Rhetoric. Edition used: 2007: Hypertext Resource Compiled by Lee Honeycutt [online]. http://www.public.iastate.edu/ honeyl/Rhetoric/index. html (13.03.2007).

Bettinghaus, Erwin P. 1968: Persuasive Communication. New York: Holt, Rinehart and Winston.

Bonnet, Gérard/Daems, Frans/Glopper, Cees de/Horner, Susan/Lappalainen, HannuPekka/Nardi, Emma/Remond, Martine/Robin, Isabelle/Rosen, Monica/Solheim, Ragnar Gees/Tonnessen, Finn-Egil/Vertecchi, Benedetto/Vrignaud, Pierre/Hansen Wagner, Aase Kari/White, Janet 2001: Culturally balanced assessment of reading (C-bar) [online]. http://cisad.adc.education.fr/reva/pdf/cbarfinalreport.pdf (14.03.2007).

Cook, Guy 1992: The Discourse of Advertising. London: Routledge and Kegan Paul.

Dacheux, Éric 1994: Les stratégies de communication persuasive dans l'Union européenne. Paris: L'Harmattan.

Görlach, Manfred 2004: Text Types and the History of English. Berlin: Walter de Gruyter.

Gorlée, Dinda L. 1994: Semiotics and the Problem of Translation. With Special Reference to the Semiotics of Charles S. Peirce. Amsterdam: Rodopi.

Gutt, Ernst-August 2000²: Translation and Relevance. Cognition and Context. Manchester: St. Jerome.

Jakobson, R. 1960: Linguistics and Poetics. In Sebeok, T.A. (ed.), Style in Language. Cambridge (Mass.): MIT Press, 350-377.

Koller, Werner 19975: Einführung in die Übersetzungswissenschaft. Heidelberg: Quelle \& Meyer.

Maylath, Bruce/Vandepitte, Sonia/Veisblat, Lucy/Humbley, John/Julliard, Claudie/ Mousten, Birthe 2005: Learning localization through trans-Atlantic collaboration. In 2005 IEEE International Professional Communication Conference Proceedings. [CD-ROM]. Limerick, Ireland.

Maylath, Bruce/Vandepitte, Sonia/Mousten, Birthe (in press): Growing Grassroots Partnerships: Trans-Atlantic Collaboration between US Instructors of Technical Writing and EU Instructors of Translation. Chapter Three in Doreen Starke-Meyerring and Ann Hill Duin (eds.), Designing Global Learning Environments. Visionary Partnerships, Policies, and Pedagogies. Rotterdam: Sense Publishers.

Mousten, Birthe/Vandepitte, Sonia/Maylath, Bruce (in press): Intercultural Collaboration in the Trans-Atlantic Project. Chapter Twelve in Doreen Starke-Meyerring and Ann Hill Duin (eds.), Designing Global Learning Environments. Visionary Partnerships, Policies, and Pedagogies. Rotterdam: Sense Publishers. 
Nord, C. 1991: Text analysis in Translation. Theory, Methodology and Didactic Applications of a Model for Translation-Oriented Text Analysis. Amsterdam: Rodopi.

Packard, Vance 1957: The hidden persuaders. New York: McKay.

Pym, Anthony 2004: The Moving Text. Localization, translation, and distribution. Benjamins Translation Library 49. Amsterdam: J. Benjamins.

Reiss, Katarina/Vermeer, Hans J. 1984/1991²: Grundlegung einer allgemeinen Translationstheorie (Linguistische Arbeiten 147). Tübingen: Niemeyer.

Vandepitte, Sonia/De Groote, Carine/Godijns, Rita/Vandamme, Mike 2006: Measuring meaning electronically? Assessti, A (self)assessment tool for the training of interpreters. In Le sens en traduction. Actes du colloque, 2-3 juin, Paris. Paris: Presses Sorbonne Nouvelle.

Vandepitte, Sonia (in press, 2008): Remapping Translation Studies: Towards a translation studies ontology. Meta, 53:3.

Werlich, E. 1982: A Text Grammar of English. Heidelberg: Quelle \& Meyer.

Whalen, D. Joel 1996: I see what you mean. Persuasive Business Communication. Thousand Oaks: Sage. 